\title{
Would you be surprised if this patient died?: Preliminary exploration of first and second year residents' approach to care decisions in critically ill patients Daniel C Johnson*1, Jean S Kutner ${ }^{1}$ and John D Armstrong II ${ }^{2}$
}

Address: ${ }^{1}$ Division of General Internal Medicine, University of Colorado Health Sciences Center, Denver, Colorado, USA and ${ }^{2}$ Center for Bioethics and Humanities, University of Colorado Health Sciences Center, Denver, Colorado, USA

Email: Daniel C Johnson* - daniel.johnson@uchsc.edu; Jean S Kutner - jean.kutner@uchsc.edu; John D Armstrong - john.armstrong@uchsc.edu

* Corresponding author

This article is available from: http://www.biomedcentral.com//472-684X/2/I

(C) 2003 Johnson et al; licensee BioMed Central Ltd. This is an Open Access article: verbatim copying and redistribution of this article are permitted in all media for any purpose, provided this notice is preserved along with the article's original URL.

\begin{abstract}
Background: How physicians approach decision-making when caring for critically ill patients is poorly understood. This study aims to explore how residents think about prognosis and approach care decisions when caring for seriously ill, hospitalized patients.
\end{abstract}

Methods: Qualitative study where we conducted structured discussions with first and second year internal medicine residents $(n=8)$ caring for critically ill patients during Medical Intensive Care Unit Ethics and Discharge Planning Rounds. Residents were asked to respond to questions beginning with "Would you be surprised if this patient died?"

Results: An equal number of residents responded that they would $(n=4)$ or would not $(n=4)$ be surprised if their patient died. Reasons for being surprised included the rapid onset of an acute illness, reversible disease, improving clinical course and the patient's prior survival under similar circumstances. Residents reported no surprise with worsening clinical course. Based on the realization that their patient might die, residents cited potential changes in management that included clarifying treatment goals, improving communication with families, spending more time with patients and ordering fewer laboratory tests. Perceived or implied barriers to changes in management included limited time, competing clinical priorities, "not knowing" a patient, limited knowledge and experience, presence of diagnostic or prognostic uncertainty and unclear treatment goals.

Conclusions: These junior-level residents appear to rely on clinical course, among other factors, when assessing prognosis and the possibility for death in severely ill patients. Further investigation is needed to understand how these factors impact decision-making and whether perceived barriers to changes in patient management influence approaches to care.

\section{Background}

Are we able to recognize when someone is dying? Previous authors have noted that there is an assumption by the public and the medical profession that the "end of life" is discernible [1]. Results from the SUPPORT study, however, suggest that our ability to detect the end of life is limited: the median predicted chance for two-month survival was no better than ' $50-50$ ' just one week before death. 
Maintaining a high suspicion for the possibility of death in moderately to severely ill patients would therefore seem prudent $[1,2]$.

To coordinate care and provide optimal support for dying patients and their families, conversations about care must occur while the patient still has a considerable chance of surviving the current illness [1,3]. Given our inability to accurately predict the end of life, it may be necessary to develop simultaneous plans in the face of serious illness: one which facilitates the support of patients and family through death and bereavement and a second which provides maximal efforts to restore physiologic balance [1,36].

How physicians approach care decisions in seriously ill, hospitalised patients remains poorly understood. Even in the critically ill, discriminating between patients who have an imminently terminal illness and those who are seriously ill, but unlikely to die soon, is difficult at best. Understanding how physicians think about prognosis in these patients - how they determine the likelihood of a patient's potential impending death - may provide insight into how care decisions are approached.

We asked internal medicine residents caring for severely ill patients "would you be surprised if this patient died?" $[7,8]$. We aimed to stimulate reflection and discussion regarding the possibility of death with the goal of better understanding how residents think about prognosis and approach care decisions when caring for critically ill patients.

\section{Methods \\ Study Design: Qualitative study}

Study participants and setting

The Internal Medicine Training Program at the University of Colorado Health Sciences Center (UCHSC) is a threeyear program that provides education for approximately 150 residents in 5 hospitals and affiliated outpatient clinics. During each of the first two years (and rarely in the third year), residents rotate through the University of Colorado Hospital (UCH) Medical intensive Care Unit (MICU) as part of a required pulmonary-critical care month. Four teams, each consisting of two first year residents (R1s), a supervising second year resident (R2), a pulmonary-critical care fellow and attending physician provide care to all patients admitted to the MICU. As these rotations occur early in training, most interns will have had little or no prior critical care experience, whereas R2s will typically have had 1-2 months of prior ICU exposure. A second hospital provides additional ICU experience for interns and R3s.
We chose to study residents at $\mathrm{UCH}$ based on an already established, comfortable forum for open discussion: Ethics and Discharge Planning (EDP) rounds. EDP rounds occur weekly and are attended by internal medicine residents, a social worker, and chaplain and, less commonly, nurses. While not excluded explicitly, the supervising fellow and/or the attending physician rarely attend EDP rounds. An ethics faculty physician (author JDA) - the coordinator of EDP rounds for more than 2 years - facilitates all discussions. On a typical afternoon, one to three residents present one or more patient cases over a 90minute period. The multidisciplinary group discusses the medical and social aspects of these cases in order to 1) assist the primary team in discharge planning and, 2) prospectively identify and clarify difficult social or ethical issues regarding the care of severely ill patients and their families.

\section{Data collection and analysis}

Following Institutional Review Board approval, we conducted structured discussions with first and second year internal medicine residents over a one-month period at EDP rounds. All residents who presented at EDP rounds during the study month agreed to participate. Participation was optional and informed consent was obtained for all interactions.

During the course of each structured discussion, residents were asked the question "Would you be surprised if this patient died?" The facilitator posed questions based on the flow diagram illustrated in Figure 1. We attempted to integrate questions into the natural flow of the discussion to minimise disruption. While we did not formally pilottest the study tool, the authors created and field-tested these questions based on prior teaching experiences (in EDP Rounds, inpatient and outpatient settings) with the "Would you be surprised" question. Author DCJ (R3) recorded meeting notes, and audiotaped and transcribed all structured discussions. Not atypical for EDP rounds, no supervising clinical faculty or nurses participated in any encounters during the study month.

Two of the authors reviewed the pattern of responses as the data was collected. We decided not to alter the original questionnaire as the 'surprise' question was generating substantial discussion about approaches to care. We used template analysis to organise and segment the data, attempting to identify major categories of responses and common domains across each category [9]. Within the framework of possible responses to the structured discussion questions and based on our $a$ priori theoretical understanding of the issues, we first defined four categories: why or why not surprised, management changes, and barriers to management changes. Initial broad domains, or codings, were identified by preliminary reading of the 


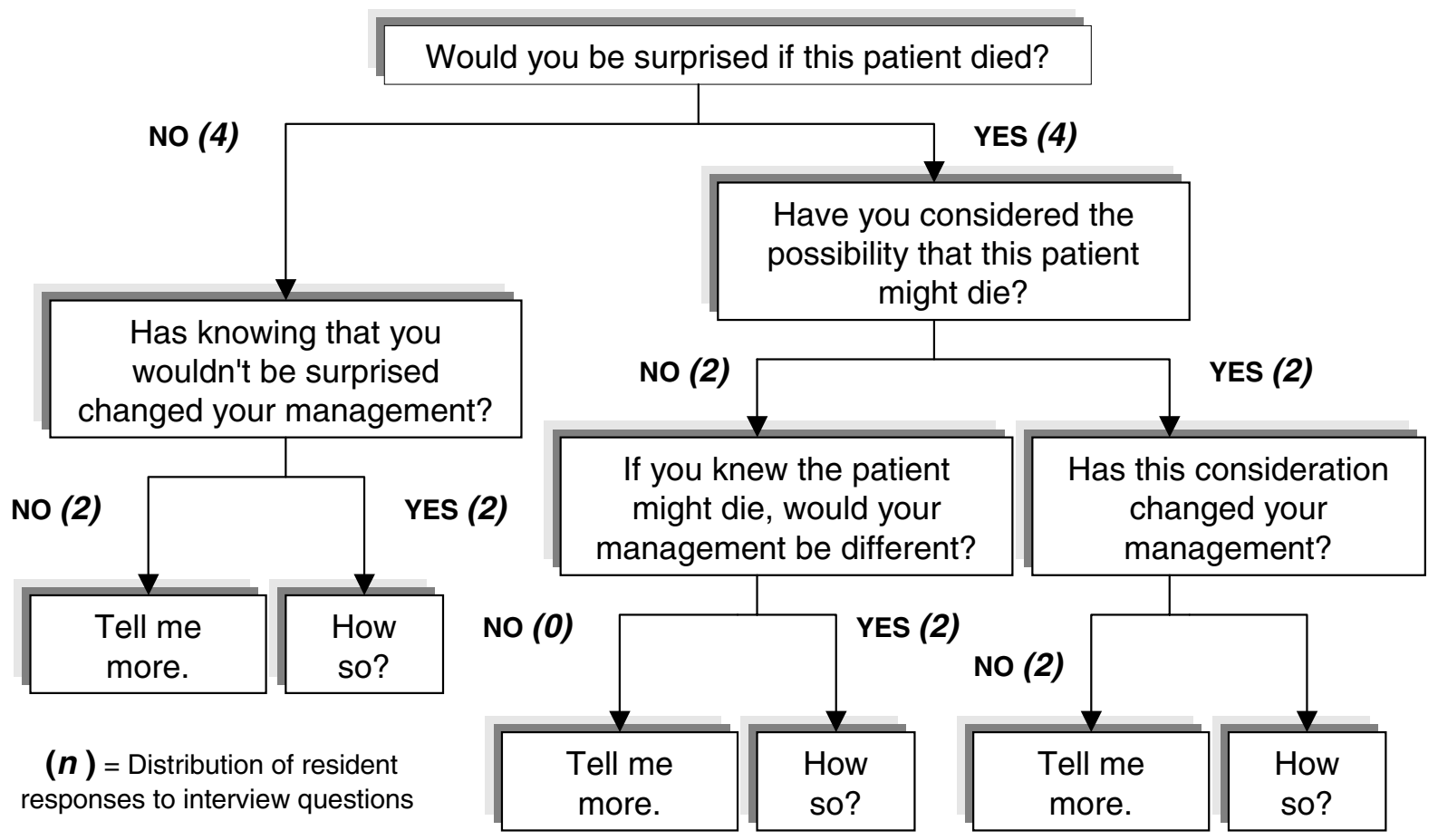

Figure 1: Flow diagram of structured interview questions.

Figure I

Flow diagram of structured discussion questions

text. Codings were refined and revised based on reflexive, iterative reading and sorting the discussion text. Independent readings and subsequent recodings of the transcriptions by two of the authors resulted in the identification of 14 salient themes among 4 broad categories of responses as described below. No unique themes emerged from analysis of responses to discussion questions of the final 3 encounters of the study.

\section{Results}

During the study month, a total of 20 residents provided care for patients in the UCH MICU: eight interns and four R2's during weeks 1-3, followed by eight different interns with the same four R2's for the last week. Over the fourweek study period, ten cases were presented at Ethics and Discharge Planning Rounds. Two patient-cases were excluded from the study: one where the patient had already died, and a second where the patient had been discharged to home prior to EDP rounds. Two patients were discussed on more than one occasion: in one instance by the same R2, and in another instance by 2 different R1s. One resident participated in the structured discussion twice during the study month. In total, we conducted eight structured discussions involving three first-year residents and four second-year residents caring for six severely ill patients (Table 1). Of the eight cases, an equal number of residents responded that they would $(n=4)$ or would not $(n=4)$ be surprised if their patient died. Figure 1 includes the distribution of resident responses to subsequent questions.

We identified four major categories of responses: 1) why residents would or 2) would not be surprised if their patients died, 3) real or expected changes in management knowing that their patient might die and, 4) barriers to changes in management. Within each category, we further 
Table I: Resident encounters: Patient characteristics

\begin{tabular}{|c|c|c|c|c|c|c|c|c|}
\hline $\begin{array}{l}\text { Encounter } \\
\quad(\mathrm{n}=8)\end{array}$ & $\begin{array}{l}\text { Resident Identifier } \\
\qquad(\mathrm{n}=7)\end{array}$ & Patient ID & Patient Age & Patient Diagnoses & $\begin{array}{l}\text { Mechanical } \\
\text { Ventilation }\end{array}$ & $\begin{array}{l}\text { Patient Time in } \\
\text { ICU }\end{array}$ & Other & $\begin{array}{l}\text { Surprised if } \\
\text { Patient Died? }\end{array}$ \\
\hline 1 & A & 1 & 70 & $\begin{array}{c}\text { Respiratory Failure, } \\
\text { Emphysema, Acute Renal } \\
\text { Failure }\end{array}$ & Yes & 3 Days & - & Yes \\
\hline II & B & 2 & 68 & $\begin{array}{l}\text { Respiratory Failure, (?) } \\
\text { Hypersensitivity Pneu- } \\
\text { monitis }\end{array}$ & Yes & 3 Weeks & Unclear Diagnosis & No \\
\hline III & C & 2 & 68 & $\begin{array}{l}\text { Respiratory Failure, (?) } \\
\text { Hypersensitivity Pneu- } \\
\text { monitis }\end{array}$ & Yes & 5 Weeks & Unclear Diagnosis & No \\
\hline IV & $\mathrm{D}$ & 3 & 38 & $\begin{array}{l}\text { Fulminate Hepatic Fail- } \\
\text { ure, Acetaminophen } \\
\text { Toxicity, Coma }\end{array}$ & Yes & I Week & - & No \\
\hline$\vee$ & $E$ & 4 & 58 & $\begin{array}{l}\text { Respiratory failure, Puru- } \\
\text { lent Pericarditis, Sepsis }\end{array}$ & Yes & 2 Weeks & Pre-Operative & No \\
\hline VI & $\mathrm{F}$ & 5 & 37 & $\begin{array}{l}\text { Fulminate Hepatic Failure } \\
\text { (Unknown aetiology) }\end{array}$ & No & 4 Days & Transplant List & Yes \\
\hline VII & G & 6 & 71 & $\begin{array}{l}\text { Congestive Heart Failure, } \\
\text { Dilated Cardiomyopathy }\end{array}$ & No & 4 Weeks & Transplant List & Yes \\
\hline VIII & $E$ & 4 & 58 & $\begin{array}{c}\text { Respiratory Failure, } \\
\text { Purulent Pericarditis, } \\
\text { Sepsis }\end{array}$ & Yes & 3 Weeks & Post-Operative & Yes \\
\hline
\end{tabular}

identified specific domains to capture common response themes. These categories, domains and illustrative quotes are depicted in Table 2.

\section{Why or why not surprised?}

We identified four domains within the category of why residents would be surprised if their patients died: the presence of a reversible disease, the rapid onset of an acute illness, improving clinical course, and prior survival under similar circumstances. Worsening clinical course was the only identified domain in cases where residents would not be surprised. One resident admitted that, while he was uncomfortable acknowledging that his critically ill patient might be dying, his patient's death would not come as a surprise.

\section{Changes in management}

Four residents proposed management changes after acknowledging that their patients might die. In three instances, these changes, whether planned or hypothetical, reflected primarily palliative behaviors [10] - clarifying care goals, improving communication with the patient and family and obtaining fewer laboratory tests. Several residents indicated that they would spend additional time speaking with patients and families about care options. Three residents implied that treatment efforts were already complete ("everything" was being done) and that, without new changes in the clinical course, no alterations to the care plan were indicated. Two residents appeared to react somewhat apprehensively, initially responding with "I don't know", and "well...you mean technically?"

\section{Barriers to changes in management}

Residents indicated that barriers within the medical system impeded potential management changes. Three residents cited lack of time as a barrier to changing management knowing that a patient might die. Five made reference to competing clinical priorities and two residents cited insufficient knowledge and experience, noting that an inadequate understanding of the natural progression of a disease limited discussions about goals of care. One resident felt that her inexperience contributed to a reluctance to suggest an alternative approach to care despite her feeling that the patient's needs were not being adequately addressed.

Other barriers to management changes were implied rather than stated. Four residents referred to the idea of "doing everything" when caring for severely ill patients. Decisions to "do everything", in some cases, appeared to encourage assumptions about a patient's and/or family's expectations. Similarly, when a patient's condition improved ("doing better"), several residents indicated that family meetings were postponed or not planned as teams narrowed treatment efforts toward sustaining physiologic gains. Two residents appeared to curtail dialogue with patients and their families knowing that their patients were not in immediate danger of dying. In one case, the uncertain aetiology of the patient's confusion resulted in the healthcare team's apparent acceptance of the patient's pain as an unavoidable complication of their diagnostic evaluation. Their primary (stated) goal - to determine the cause of the patient's confusion - appeared to overshadow concerns for pain relief. 
Table 2: Representative resident responses by category and domain

\begin{tabular}{|c|c|}
\hline CATEGORY I: Why surprised? & \\
\hline Domain & Example \\
\hline Presence of a reversible disease & $\begin{array}{l}\text { - "...Because initially it was thought to be a hypersensitivity pneumonitis } \\
\text { - a reversible disease. We weren't really thinking about her dying." }\end{array}$ \\
\hline Rapid onset of an acute illness & $\begin{array}{l}\text { - "You know, it happens so quickly sometimes. She was all right a week } \\
\text { ago, and suddenly she's here in the ICU. We've been mostly concentrat- } \\
\text { ing on making her better." }\end{array}$ \\
\hline \multirow[t]{3}{*}{ Improving clinical course } & • "Surprised? Yeah - I guess so... I think she's much better." \\
\hline & $\begin{array}{l}\text { - "Maybe we did at first, but his enzymes are coming down now. I think } \\
\text { it's probably more likely that he'll wake up." }\end{array}$ \\
\hline & $\begin{array}{l}\text {-I would be surprised then too. Nothing was that much different - she } \\
\text { was doing OK." }\end{array}$ \\
\hline Prior survival under similar circumstances & $\begin{array}{l}\text { "...He has been in before, though, for dobutamine and he's done fine. I } \\
\text { think that's why they continue to want everything done." }\end{array}$ \\
\hline
\end{tabular}

CATEGORY 2: Why not surprised?

\section{Domain}

Worsening clinical course

\section{Example}

- "I wouldn't be surprised. She's [now] been intubated for the last three or four days."

- Facilitator: "Could it be that she is now dying?"

Resident: "Dying? Well, she's definitely getting worse. I'm not sure l'd say she's dying."

Facilitator: "Would you be surprised if she died?"

Resident: "No...not when you ask it that way."

\section{CATEGORY 3: Changes in management}

\section{Domain}

\author{
Clarifying goals
}

Improving communication with patients and families

Spending more time with patients/ ordering fewer labs

\section{Example}

- "When you're talking about working up - micromanaging - every little thing, you should probably figure out [what] the family and patient would really want. ... I think [that] talks with the family would clarify these things."

- "Yeah, I would probably spend more time with the patient and the family - and [I would] listen to their story."

- "...l'd probably spend more time with the patient - you know, getting to know his wishes. And l'd order less labs - since it wouldn't make much difference."

CATEGORY 4: Barriers to changes in management

\section{Domain}

Limited time

Competing clinical priorities

\section{Example}

- "And you don't have time - unless you're doing an ethical rotation where you can sit down and talk to a patient for an hour and a half. Usually you get done with everything and [realize], "oh, I didn't ask them about cor status" - and what they would want done. ...You can't explain what all the options are."

- "...There's a bunch of family things that I need to follow up on. And those end up being, in my mind, the most important - but the nurses are like "you've got to have the morning labs and the $x$-ray requests filled out." I'm just trying to play catch-up." 
Table 2: Representative resident responses by category and domain (Continued)

\begin{tabular}{|c|c|}
\hline & $\begin{array}{l}\text { - "Well, just the intubation...just keeping someone on an FiO2 of over } 80 \\
\text { percent and the damage it causes. She'll get much worse - [and] we'll } \\
\text { have to address those problems when they come. I'm hoping not, } \\
\text { though." }\end{array}$ \\
\hline Not knowing a patient & $\begin{array}{l}\text { "Well, for me, I came on the service with ten new patients and we } \\
\text { were on call... The next day I was off... So I just feel I still don't really } \\
\text { know these patients." }\end{array}$ \\
\hline Limited knowledge and experience & $\begin{array}{l}\text { - "And it's also hard for me - as an intern. ... And I don't feel like I know } \\
\text { enough about ICU medicine - I have no idea what chronic acetami- } \\
\text { nophen toxicity... what the outcome is. ...If I knew more about people's } \\
\text { outcomes, I would be pushing one way or the other." }\end{array}$ \\
\hline \multirow[t]{3}{*}{ The presence of diagnostic or prognostic uncertainty } & $\begin{array}{l}\text { - Resident: "...So the problem is she was found to have a normal CT scan, } \\
\text { and now has diffuse cerebral oedema. We don't know how much of it is } \\
\text { contributing to her mental status." }\end{array}$ \\
\hline & Nurse: "ls the pain service involved?" \\
\hline & $\begin{array}{l}\text { Resident: "No, and I guess the fear is that we narc her too much to know } \\
\text { what really is going on with her mental status. I'm not really comfortable } \\
\text { doing that ..." }\end{array}$ \\
\hline \multirow[t]{3}{*}{ Unclear goals } & $\begin{array}{l}\text { - "I spoke with the aunt on the day after she was admitted and, of } \\
\text { course, they want everything done.... I think they are blinded to the fact } \\
\text { that this does not look good, given her mental status. ...And I don't } \\
\text { know how much she knows, but they want everything done..." }\end{array}$ \\
\hline & $\begin{array}{l}\text { - "..I haven't talked with her for a couple of days, but I know that she } \\
\text { sees that her mom is doing better. It's still not clear if she is the best one } \\
\text { to be making decisions, but the family is still working that out. We } \\
\text { haven't had a family meeting since last week - mostly because she is } \\
\text { doing so much better." }\end{array}$ \\
\hline & $\begin{array}{l}\text { - "... We're focusing on making her better. ...I'm not sure if the family } \\
\text { completely agrees, but for now they see how she's improving with } \\
\text { what's been done. ...There's really not many decisions to make unless } \\
\text { she gets sicker again." }\end{array}$ \\
\hline
\end{tabular}

\section{Discussion}

In this study, we use the question "would you be surprised if this patient died" to explore how residents think about their critically ill patients. This inquiry appears to stimulate reflection and dialogue about the potential for a patient's death and, as hinted by one resident's response, may be less threatening than "is your patient dying?" As such, this approach may offer physicians a "safer space" to acknowledge the possibility of death by encouraging reflection without impugning a physician's intentions or competence.

These encounters provide preliminary insight into how residents think about prognosis when caring for seriously ill, hospitalised patients. Residents appear to frequently utilise clinical course - whether a patient is getting better or worse - to determine the likelihood of a patient's death. This may be an important finding, as this iterativetype approach is unlike common prognosticating instruments such as the APACHE or SUPPORT score, which attempt to determine prognosis based on a single evaluation $[11,12]$. Traditional prognostic tools might also fail to capture other elements cited by residents when assessing a patient's likelihood of dying: prior survival under similar conditions, reversibility of the disease, and sudden onset of an acute illness. Previous authors have noted that quantitative models are rarely used in clinical practice [13] - in part, because clinicians may not know how to use them in a meaningful and effective way [14], and such models apply to populations and fail to account for the uniqueness of the individual [15]. While the accuracy of the resident-reported elements remains unknown, perhaps prognostic models that account for prior experience and trajectory of the illness may be more clinical useful and intuitively understandable to patients, families and providers.

This study identifies several potential barriers to management changes after recognising that a patient might be dying. Understanding these barriers - whether real or perceived - may be important in efforts to improve ICU care. Multiple residents cited "lack of time" as a barrier to changing management once their patient had been identified as possibly dying. This may reflect the current culture of medical training: in one prior study, $80 \%$ of surgical residents reported feeling constrained by time when caring for terminally ill patients and their families [16]. Alternatively, residents might be using lack of time as an excuse - either consciously or otherwise - to avoid difficult, seemingly time-intensive conversations with pa- 
tients and families. As such, this perceived barrier might highlight a potential misconception that not talking with patients takes less time. A time flow study might help to clarify the validity of this perception.

Residents may not recognise or explicitly express other important, real barriers. For example, the cited responses suggest that residents seek to present themselves as selfgoverning, autonomous decision-makers, when in fact they may be strongly influenced by the cultural milieu of the ICU. Residents may fail to recognise or admit the importance of peer pressure or "conforming to the norm" in their decision-making. Furthermore, the ICU cultural milieu may profoundly impact how residents prioritise responsibilities. Balancing competing demands within a "cult of curability" may encourage physicians to evaluate success on the basis of curing, rather than on the basis of providing the best care for patients [17]. In such a system, it is easy to imagine how a resident's reluctance to propose alternative care approaches could result from intimidation by the accepted system rather than her own self-acknowledged lack of experience. Feelings of increased stress and less collegial support when managing dying patients might further contribute to this apprehension [18].

Another potential barrier is suggested by residents' frequent references to "doing everything". It is often misleadingly assumed in this phrase that there exists some common understanding of what "everything" entails. While some residents may have had detailed conversation with patients and families, resident responses seem to suggest otherwise - that care goals were often poorly understood. Statements like "we are doing everything" or "there is nothing more we can do" likely mirror the culture of medical training. McCue, in a 1995 JAMA article, describes medicine as a "culture of action" - it is better to do something (more tests, another medication) than to do nothing, even if the action is known to have no benefit [18]. In one study, almost half (47\%) of physicians and nurses surveyed reported acting contrary to conscience in providing care to the terminally ill, with four times as many providing overly burdensome treatment than undertreatment [19]. The propensity to refer to "everything", even in cases with specific known goals, might inadvertently promote futile attempts to prolong life and deflect attention away from patients' pain and suffering. Understanding why we choose such language, whether due to a poor understanding of specific goals or simply a convenient construct for describing curative care, might help in the design of practical interventions that would promote more comprehensive care.

Some residents were quite hesitant about answering questions regarding changing management. While this openended inquiry is inherently ambiguous, these apprehen- sive responses might also suggest residents' discomfort with changing a plan recommended by supervising physicians. Alternatively, the hesitation may also highlight residents' discomfort with managing patients who may be dying. Medical education traditionally focuses on training physicians to diagnose, cure and prolong life, with only minimum attention given to the techniques of caring for the patient for whom cure is of less relevance [20,21]. An ABIM survey of more than 1400 IM residents found that $72 \%$ reported receiving adequate training in managing pain and other symptoms, $62 \%$ in breaking bad news to patients, $38 \%$ in educating the patient and family about the dying process and $32 \%$ in responding to patients who request assistance in dying $[22,23]$. Further heightening apprehension might be residents' emotional inexperience, especially in an environment where the emotional needs of care providers may be inadequately addressed.

Likewise, physicians may also lack the skill to recognise or elicit the needs of patients and their families. Eric Cassell writes that this lack of recognition and treatment of suffering does not come about because of an absence of compassion or concern, but more often results from physicians' poor diagnostic and therapeutic knowledge and skills about persons. Cassell challenges physicians to learn and teach methods in "empathic attentiveness" in order to know patients as individual persons well enough to understand the origin of their suffering and ultimately its best treatment [24].

How might the information from this study help to improve patient care? First, this study hints that at least some residents may be more inclined to think about the concurrent palliative needs of patients and families after considering the possibility that their patients may be dying. The surprise question, as such, could be a direct means to impacting breadth of care. Future studies might prospectively examine variation in care management following this routine inquiry coupled with follow-up questions such as "Has asking this question changed your opinion about whether the patient might dying?" or "Will you change your management of the patient because I asked this question?" As Eric Cassell notes, the act of consciously thinking about information, whatever its origins - numbers on a printout, a report of pain, or in this case, the possibility for death - makes it objective, an object of consciousness [24].

Second, clinical course and other factors appear to influence communication - knowingly or not - with patients and their families. Some of these residents appear to postpone or avoid potentially goal-defining conversations with patients and families if the chance for immediate death seems unlikely or remote. As many patients and families may embrace an approach of "doing everything" 
in cases where the disease trajectory is not straightforward, postponing conversations regarding goals of care may effectively limit care options until no more curative treatments remain and such discussions become a practical necessity. More in-depth studies are needed to better understand how and to what extent these factors alter decision-and communication in the ICU setting.

This study has multiple limitations. First, whether the findings from this small exploratory study are transferable to a broader sample of interns and residents is unknown. Although this study was integrated into a real-world, established setting, the core question may not provide similar insightful dialogue in other venues. From at least the general perspective of medical education, these observations seem relevant. While the credibility of the study is enhanced through the facilitating faculty's 2 years of EDP field experience, member checking - reviews from the participating residents - and independent peer examination would have increased validity [25]. More purposive sampling governed by emerging insights would have helped to clarify details of the promising themes. Next, it is unlikely, given the limited encounters, that saturation of resident responses was achieved. Although no new themes emerged during the last several interactions, we chose to not to collect additional data, in part, because the primary goal of this study - to provide a basic, preliminary framework into how residents approach decisions in the ICU had been achieved. We believe these preliminary data support more extensive exploration of identified themes. While following the question flow diagram provided a consistent inquiry, the dependability of the process may have been compromised by not specifying a time frame with the question "would you be surprised"? An additional assessment of study dependability or confirmability through audit would have improved the trustworthiness of these data. Finally, we did not account for differences between patients' severity of illness, variations in residents' critical or palliative care experience, comfort in caring for dying patients or the influence of the fellow or attending physician on management decisions. Capturing data on these other factors would have helped define their potential influence on resident responses.

\section{Conclusions}

Whether asking the question "would you be surprised if this patient died?" might serve to alter care by illuminating the possibility of death warrants further investigation. Although much work remains, preliminary insight suggests these selected physicians-in-training depend highly on clinical course, among other factors, when approaching decisions regarding the care of severely ill patients. Understanding how these factors influence communication may help to illuminate why previous attempts to im- prove care for critically ill patients and their families have been disappointing.

\section{Competing interests}

None declared.

\section{Authors' contributions}

DJ participated in the design, data collection, analysis, and drafting of the manuscript.

JK participated in the design, data analysis, manuscript editing.

JA participated in the design, data collection and manuscript editing.

\section{References}

I. Lynn J, Harrell F, Cohn F, Wagner D and Conners AF Prognoses of seriously ill hospitalised patients on days before death: implications for patient care and public policy. New Horiz 1997, 5:5661

2. The Support Investigators The study to understand prognoses and preferences for outcomes and risks of treatments. JAMA 1995, 274:159|-1598

3. Lynn J, Teno JM and Harrell FE Accurate prognostications of death: opportunities and challenges for clinicians. West J Med 1995, 163:250-257

4. Leland JY and Schonwetter RS Advances in hospice care. Clin Geriatr Med I 997, 13:38I-399

5. Cherny $\mathrm{NI}$ and Catane R Palliative medicine and the medical oncologist: defining the purview of care. Hematol Oncol Clin North Am 1996, 10: I-20

6. Von Gunten CF and Twaddle M Terminal care for noncancer patients. Clin Geriatr Med 1996, 12:349-358

7. Lynn J and Berwick D From published attachment: 20 improvements in end of life care - changes internists could do next week. Adapted from a handout by Americans for Better Care of the Dying [www.abcd-caring.org] accompanying the keynote speech by Dr. Berwick, Institute for Healthcare improvement, ACP-ASIM Annual Meeting, April, 1999 and Dr. Lynn's Testimony before the Senate Special Committee on Aging July 2000

8. Christakis NA Death foretold: prophecy and prognosis in medical care. Chicago, University of Chicago Press 2000,

9. Crabtree BF and Miller WL A template approach to text analysis: developing and using codebooks. In: Research methods for primary care: Doing qualitative research (Edited by: Crabtree BF, Miller WL) Newbury Park, Sage Publications Inc 1992, 93-109

10. Singer PA, Martin DK and Kelner M Quality end-of-care: patients' perspective. JAMA 1999, 281:163-168

II. Knaus WA and Zimmerman JE APACHE - acute physiology and chronic health evaluation: a physiologically based classification system. Crit Care Med 198I, 9:59I-597

12. Knaus WA and Harrell FE Jr The SUPPORT prognostic model. Ann Intern Med 1995, 1 22:191-203

13. Christakis $\mathrm{N}$ and Iwashyna $\mathrm{T}$ Attitude and self-reported practice regarding prognostication in a national sample of internists. Arch Intern Med 1998, I 58(2 I):2389-2395

14. Lynn J Ineffectiveness of the SUPPORT intervention: Review of explanations. J Am Geriatr Soc 2000, 48 (5 suppl):S206-A2 I 3

15. Hadorn DC Kinds of patients. J Medicine and Philospohy 1997, 22(6):567-587

16. Rappaport W, Prevel C, Witzke D, Fulginiti J, Ballard J and Wachtel T Education about death and dying during surgical residency. Am J Surg 1991, 161:690-692

17. Feldman A The dying patient. Psychiatr Clin North Am 1987, 10:101108

18. Sand RB, Blackall GF, Abrahm JL and Healey K A survey of physicians' education in caring for the dying: identified training needs. J Cancer Educ 1998, 13:242-247 
19. Jecker NS Medical futility and care of dying patients. West J Med 1995, 163:287-29|

20. Mount BM Dealing with our losses. J Clin Oncol I 986, 4: I I 27-I I 34

21. Weissman DE, Block SD, Blank L, Cain J, Cassem N, Danoff D, Foley K, Meier D, Schyve P, Theige D and Wheeler HB Recommendations for incorporating palliative care education into the acute care hospital setting. Acad Med 1999, 74:87I-877

22. Billings JA and Block SD Palliative care in undergraduate medical education: status report and future directions. JAMA I997, 278:733-738

23. Blank LL Defining and evaluating physician competence in end-of-life patient care: a matter of awareness and emphasis. West J Med 1995, 163:297-301

24. Cassell EJ Diagnosing suffering: a perspective. Ann Intern Med 1999, I 3 I:53|-534

25. Lincoln $Y$ and Guba E Naturalistic Inquiry. Newbury Park, CA, Sage Press 1985

\section{Pre-publication history}

The pre-publication history for this paper can be accessed here:

http://www.biomedcentral.com/1472-684X/2/1/prepub

Publish with Bio Med Central and every scientist can read your work free of charge

"BioMed Central will be the most significant development for disseminating the results of biomedical research in our lifetime."

Sir Paul Nurse, Cancer Research UK

Your research papers will be:

- available free of charge to the entire biomedical community

- peer reviewed and published immediately upon acceptance

- cited in PubMed and archived on PubMed Central

- yours - you keep the copyright

Submit your manuscript here:

http://www.biomedcentral.com/info/publishing_adv.asp 